\title{
mtDNA analysis of the Galician population: a genetic edge of European variation
}

\author{
A ntonio Salas ${ }^{1}$, D avid Comas ${ }^{2}, M$ aría Victoria $L$ areu $^{1}$, Jaume Bertranpetit ${ }^{2}$ and \\ A ngel Carracedo ${ }^{1}$ \\ ${ }^{1}$ Institute of L egal M edicine, U niversity of Santiago de Compostela, Spain \\ ${ }^{2} \mathrm{~L}$ aboratori d'A ntropologia, Facultat de Biologia, U niversitat de B arcelona, Spain
}

\begin{abstract}
Analysis of mitochondrial DNA (mtDNA) variation has become a useful tool for human population studies. We analysed the first hypervariable region of mitochondrial DNA control region (position 16024-16383) in 92 unrelated individuals from Galicia (Spain), a relatively isolated European population at the westernmost continental edge. Fifty different sequences defined by 56 variable positions were found. The frequency of the reference sequence reaches in Galicians its maximum value in Europe. Moreover, several genetic indexes confirm the low variability of our sample in comparison to data from 11 European and Middle Eastern populations. A parsimony tree of the sequences reveals a high simplicity of the tree, with few and small well defined clusters. These results place Galicians on the genetic edge of the European variation, bringing together all the traits of a cul-de-sac population with a striking similarity to the Basque population. The present results are fully compatible with a population expansion model in Europe during the Upper Paleolithic age. The genetic evidence revealed by the analysis of mtDNA shows the Galician population at the edge of a demographic expansion towards Europe from the Middle East.
\end{abstract}

Keywords: mtDNA; control region; Galicians; neighbour joining tree; pairwise difference distribution

\section{Introduction}

Much has been learnt about human population history and evolution through genetic analysis, Europe being the most comprehensively studied area in the world. $U$ ntil recently, most of the information came from what are known as 'classical genetic marker' studies, where the analyses were based on geographic variation of

Correspondence: J B ertranpetit, L aboratori d'A ntropologia, Facultat de B iologia, U niversitat de B arcelona, D iagonal 645, 08028 Barcelona, Spain. Tel: 3493 4021461; Fax: 3493 4110887; E-mail: jaumeb@porthos.bio.ub.es

R eceived 27 M ay 1997; revised 19 January 1998; accepted 26 January 1998 allele frequencies for expressed genetic polymorphisms. When genetic information has been widely available for a given geographic region and data has been properly handled (be it through genetic distances, principal components or other numerical tools) it has been possible to make interesting and innovative proposals about the knowledge of our past. The exhaustive compilation of Cavalli-Sforza et al $^{1}$ stresses the long standing interpretation of the genetic variation in Europe as being primarily shaped by the demographic impact of the Neolithic expansion. Besides this principal general pattern, some populations have shown genetic peculiarities (in the sense that they show clear 
differentiation from neighbouring populations) which can be understood in terms of differences in allele frequencies due to specific events of genetic drift in their history. This is the case for the B asques, Sardinians, Finns, Saami, Icelanders and several populations of the Caucasus. As drift is the main factor for the genetic differences of these populations in relation to their geographic neighbours, allele frequency comparisons may not inform us about the origin of a given population. R ather, they refer to the last drift episode (bottleneck, founder effect) which has taken place in population history, ie the last episode of isolation with a small sample size. However, the genetic origin of the population may be much older. This is what seems to be revealed in the analysis of other genomic regions, mostly DNA sequences. The amount of variation in sequences may be maintained through a bottleneck due to the fact that most genetic lineages (or representative of most phylogenetic branches) may survive through dramatic changes in population size while other sequences may be lost. Although some sequence studies exist for autosomic regions (see Ref 2 for important methodological developments), mitochondrial DNA (mtD NA) has been largely the molecule of choice for most of the recent studies, especially in Europe. Three partial and somewhat contradictory syntheses have been published recently on mtDNA variation and the origin of $E$ uropeans. . $^{3-5}$

The present analysis tries to shed light on the general European genetic variation view by studying the westernmost E uropean geographical edge (the R oman Finisterrae, the end of the $E$ arth) through the analysis of the mtDNA hypervariable region I of the Galician population. Galicia is a region situated in the northwest extreme of the I berian Peninsula (Figure 1) with specific characteristics. Its geographical isolation from the rest of the Iberian Peninsula, in addition to its migratory patterns (with high emigration rates throughout centuries and almost no immigration), has preserved its identity, language, economy and especially its own cultural identity.

Within the Iberian Peninsula not only Galicia but also the rest of the Cantabrian Coast showed a specific pattern in prehistoric times. During Paleolithic and $M$ esolithic times, all the Cantabrian region was a very homogenous area, differentiated from the rest of Iberia. E cological and nutritional resources were similar along all the North I berian coast, richer than in the rest of the Peninsula. The Basques, outliers in the genetic landscape of Europe, as shown by classical genetic markers, ${ }^{1,6}$ are also located in this Cantabrian area. M oreover, G alicia seems to have been influenced by $A$ tlantic cultures mainly during the first millennium $\mathrm{BC}^{7,8}$ and Celtic influences are still found in some cultural traits.

The proximity of the present population to the genetically well-known Basques and its peripheral position in European geography make Galicia especially interesting for the understanding of population affinities, history and for refining the geography of genetic variation in Europe.

\section{Material and Methods}

Population Samples

B lood samples were obtained from 92 healthy autochthonous unrelated individuals scattered through Galicia. DNA was extracted using a phenol-chloroform procedure ${ }^{9}$ and quantified using a H oefer D yNA Q uant 200 Fluoremeter (Pharmacia, U ppsala, Sweden).

\section{mtDNA Amplification and Sequencing}

A semi-nested PCR was performed in order to amplify the first hypervariable segment of the mtDNA control region. The first amplification was carried out in a Perkin E Imer 480 A Thermocyler (Perkin EImer, Foster City, CA , U SA ) using

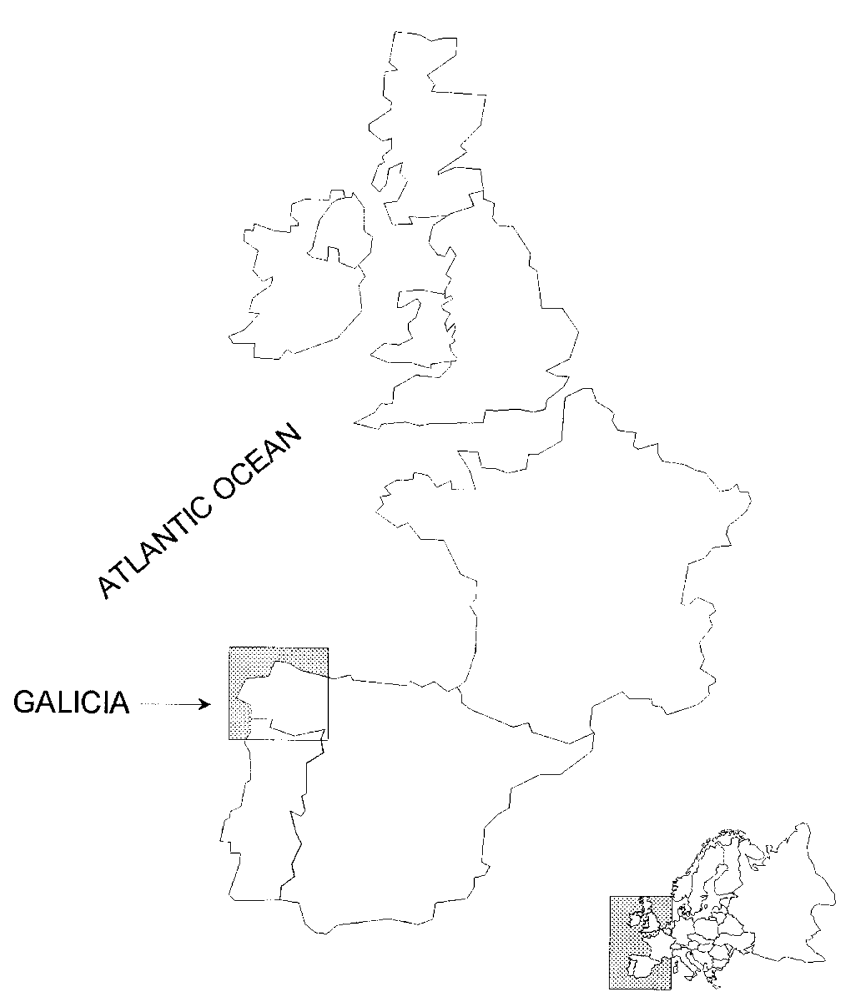

Figure 1 L ocation of $\mathrm{G}$ alacian population in the western corner of Europe 
$5 \mathrm{ng}$ of DNA in $25 \mu \mathrm{l}$ reaction volume, following a temperature profile for 32 cycles of amplification at $95^{\circ} \mathrm{C}$ for $1 \mathrm{~min}, 55^{\circ} \mathrm{C}$ for $1 \mathrm{~min}$, and $72^{\circ} \mathrm{C}$ for $1 \mathrm{~min}$. A segment of 1021 base pairs was amplified using the L 15997 ( $5^{\prime}$-CA C CATTA G CA CCCA A A G CT-3') ${ }^{10}$ and H 408 (5'-CTGTTAA A A GTG CATACCGCCA $\left.-3^{\prime}\right)^{11}$ primers. The nomenclature of the primers refers to the light and heavy chains of the mtD NA ( $L$ or $\mathrm{H}$ ), and the numbers identify the position of the primer $3^{\prime}$ ends in the reference Cambridge sequence. ${ }^{12}$ The second PCR amplification was performed using primers $L 15997^{10}$ and H 16401 (5'-T GATTTCA CG GA A G GATG T T - $3^{\prime}$ ), ${ }^{11}$ which amplified a fragment of $443 \mathrm{bp}$, with a temperature profile for 32 cycles of amplification of $95^{\circ} \mathrm{C}$ for $1 \mathrm{~min}, 60^{\circ} \mathrm{C}$ for $1 \mathrm{~min}$, and $72^{\circ} \mathrm{C}$ for $1 \mathrm{~min}$. Positive and negative controls were checked in the PCR amplifications in order to detect possible contamination.

The PCR products were purified with MICROSPIN ${ }^{\mathrm{TM}} \mathrm{HR}$ S-300 columns (Pharmacia B iotech, U ppsala, Sweden) before the cycle sequencing. The sequence reactions were carried out using the PCR Fentomol Sequencing K it (Promega, M adison, USA ) with $100 \mathrm{ng}$ of template DNA and $0.5 \mu \mathrm{m}$ of fluorescently labelled sequencing primers ( $\mathrm{L} 15997$ and $\mathrm{H}$ 16401). The sequencing profile for 10 cycles was, $95^{\circ} \mathrm{C}$ for $30 \mathrm{~s}, 55^{\circ} \mathrm{C}$ for $30 \mathrm{~s}$ and $70^{\circ}$ for $90 \mathrm{~s}$, followed by an extension cycle at $72^{\circ} \mathrm{C}$ for $5 \mathrm{~min}$.

The sequence products were denatured with deionizide formamide and run in a $6 \%$ PAGE gel, and analysed in an A LF automatic sequencer (Pharmacia, U ppsala, Sweden).

Site 73 of the second hypervariable region has also been tested in 71 individuals under a more exhaustive analysis of mtDNA sequence (Salas et al, manuscript in preparation).

\section{Computer Analysis}

The alignment of the sequences obtained was performed using the CLUSTA L W (1.5) Multiple Sequence A lignment program. ${ }^{13}$ The final information for each individual was a string of 360 characters belonging to the mtDNA hypervariable region I ( $\mathrm{HVI}$ ), from base position (16024 to $16383 .{ }^{12}$ Sequences are available by e-mail on request to apimlase@uscmail.usc.es. For most calculations, the standard package PHY LIP $3.5 c^{14}$ was used, and some programs were specifically written.

To test the internal diversity of the sample, several parameters were computed. N ucleotide diversity ${ }^{15}$ was estimated as $(n / n-1)(1 / l) \Sigma_{i=1}^{1}\left(1-x_{i}^{2}\right)$, where $n$ is sample size, $I$ is sequence length (360, in the present study) and $x_{i}$ is the frequency of each nucleotide at position i. Similarly, sequence diversity was estimated as $(n / n-1) \Sigma_{i=1}^{k}\left(1-p_{i}^{2}\right)$, where $p_{i}$ is the frequency of each of the $k$ different sequences in the sample. Finally, Shannon's measure of information $H$, defined as $H=-\sum p_{i} \log _{2} p_{i}$ (where $p_{i}$ is the sample frequency of the ith sequence), and $\mathrm{H}^{\prime}$ (the ratio of $\mathrm{H}$ to its maximum value for a given sample size: $-\log _{2}(1 / n)$, where $n$ is the sample size), ${ }^{16}$ were calculated in order to measure the genetic diversity of the sample.

Pairwise difference distribution was computed, and the $\tau$ parameter from the two-parameter model of $\mathrm{H}$ arpending et $\mathrm{al}^{17}$ was obtained. Standard errors were computed from 1000 bootstrap iterations: resampled sequences of the same length (360 characters) were obtained by sampling sites with replacement.

$D$ ata from different populations were used for comparison: 106 Basques, ${ }^{18,19} 92$ Welsh, ${ }^{4} 54$ Portuguese, ${ }^{19} 69$ Cornish, ${ }^{4} 49$
B avarians, ${ }^{4} 108$ northern Germans, ${ }^{4} 100$ British, ${ }^{20} 89$ Spanish, ${ }^{19,21} 49$ Tuscans, ${ }^{22}$ 96 Turks, ${ }^{4,23,24}$ and $42 \mathrm{M}$ iddle E asteners. ${ }^{25}$ A genetic distance matrix between populations was obtained by using the intermatch-mismatch distance: $D=d_{i j}-$ $\left(d_{i i}+d_{i j}\right) / 2$, where $d_{i j}$ is the mean number of intermatches between populations $i$ and $j$, and $d_{i i}$ and $d_{j j}$ are the mean pairwise differences (mismatches) within populations $i$ and $j$. This expression is known as the Jensen difference and was defined by $\mathrm{Rao}^{26}$ It is related to the pairwise difference distributions, which have been studied and modelled intensively. ${ }^{17,27}$ Standard errors were estimated by bootstrap. ${ }^{28}$ Neighbour-joining trees were built from the distance matrix using the options NEIGHBOUR and DRAWTREE in the PHYLIP package and the robustness of the clusters found was estimated by bootstrap ${ }^{29}$ using the option SE Q B O OT in the same package.

\section{Results}

\section{Sequence diversity}

A total of 53 different sequences defined by 56 variable positions were found (Table 1). A II the polymorphisms observed in the sample were nucleotide substitutions, except for a deletion found in one individual of one $A$ in the run of three A s which goes from position 16349 to 16351 . Of the 55 remaining variable positions, 50 were transitions, three were transversions and two presented both types of substitutions (positions 16093 and 16114). The variable sites present the following pattern: $41 \mathrm{~T}<->\mathrm{C}, 11 \mathrm{~A}<->\mathrm{G}, 2 \mathrm{~T}<->\mathrm{G}, 2$ $\mathrm{A}<->\mathrm{C}, 1 \mathrm{~A}<->\mathrm{T}$; 11.6:1 being the ratio between transitions and transversions. There is a clear bias in the proportion of the pyrimidine transitions (found 117 times across all sequences) with respect to purine transitions (found 24 times in all sequences). Nevertheless, this proportion is common in a large worldwide sequence set. ${ }^{30}$ For all the positions, the most frequent nucleotide is that shown by the reference sequence, and only two positions present high levels of polymorphism: position 16126 ( $T$ in the reference sequence) with a $C$ in 11 individuals (12\%), and position 16311 ( $T$ in the reference sequence) with a C in 10 individuals (10.9\%) in the sample.

It is interesting to note that 24 individuals presented the reference sequence, ${ }^{12}$ the highest frequency $(26.1 \%)$ observed in the whole set of populations used for comparison. Some of the remaining sequences were shared by a few individuals: three different sequences were found three times $(9.8 \%)$, ten sequences twice $(21.7 \%)$ and 39 individuals had unique sequences $(42.4 \%)$ ); this represents a low level of variability within the sample and, phylogenetically, all sequences are closely related. 
Table 1 mt DNA sequences of the hypervariable region HV 1 found in 92 Galician individuals, compared to R ef. 12. Dots indicate identity with the reference sequence, and deletion is represented by a dash. $\mathrm{N}$, indicates the number of individuals. Sequences are sorted according to the groups suggested by Richards et al. 4 The two last columns show the number of individuals ( $a$ total of 71 ) having an A or a $\mathrm{G}$ in position 73 of the hypervariables region $\mathrm{HV} 2$

111111111111111111111111111111111111111111111111111111111111

666666666666666666666666666666666666666666666666666666666 000000011111111111111222222222222222222222222222222233333

256789912224666678899901111122223334444567788999999901456

$549263444695234924923573678912344590123610878123456841962 \mathrm{~N} 3$

ANDERSON TACCTTTCTTGGAAACTCTCCTAGATCACCCTCACAACTCCCCCTCCACCCT T TATT

SEQ1

SEQ2

SEQ3

SEQ4

SEQ5

SEQ6

SEQ7

SEQ8

SEQ9

SEQ10

SEQ 11

SEQ12

SEQ13

SEQ 14

SEQ 15

SEQ 16

SEQ 17

SEQ 18

SE Q 19

SEQ20

SEQ21

SEQ 22

SEQ23

SEQ 24

SEQ 25

SEQ26

SEQ27

SEQ28

SEQ 29

SEQ 30

SEQ31

SEQ 32

SEQ40

SEQ 41

SEQ44

SEQ 46

\section{G}

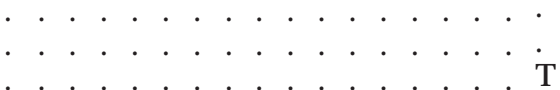

G. . . . . . .

C

$\mathrm{G}$
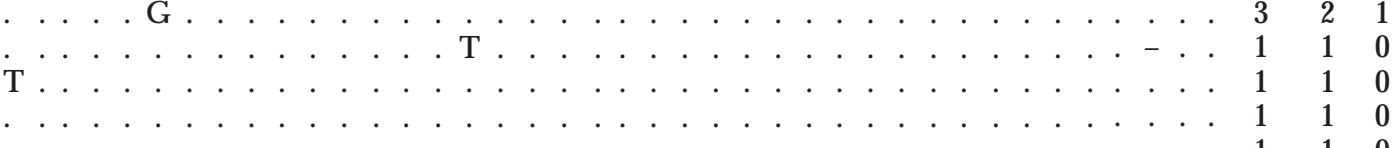

21

c.

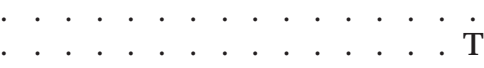

C

C

$\dot{\mathrm{T}}$

SEQ47

SEQ48

SEQ 49

SEQ50

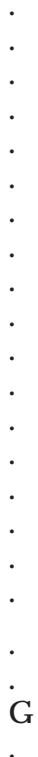




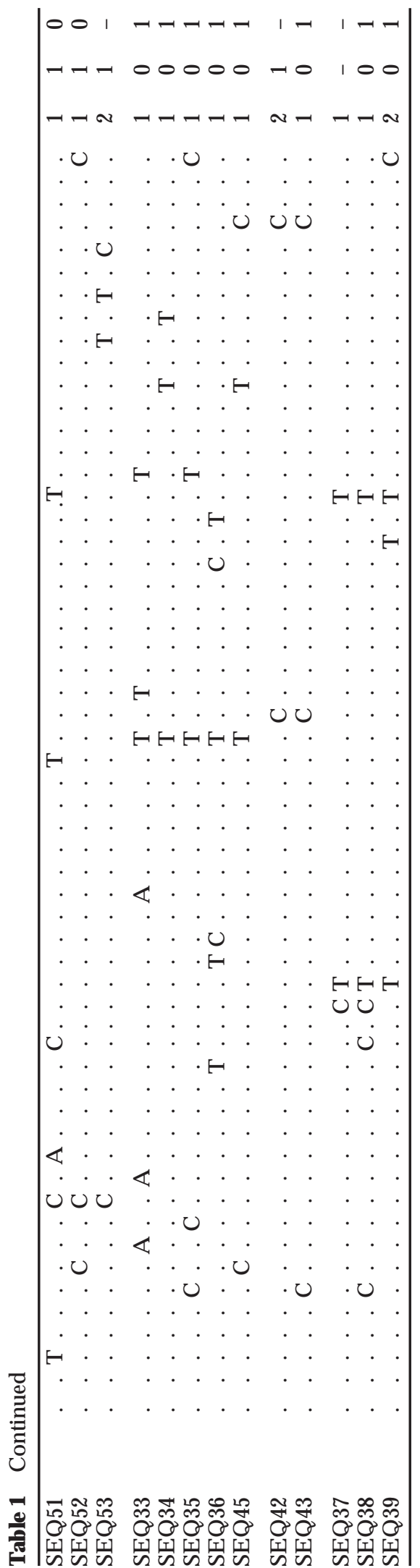

Sequence diversity (0.9295), nucleotide diversity (0.0087) and Shannon's index $H^{\prime}(0.865)$ shown in Table 2, present very low values in comparison to other European populations, reflecting again the phylogenetic simplicity in the mtDNA variation. The values obtained for these parameters show a clinical gradient from West A sia to Western E urope, with B asques and $G$ alicians being the populations with the lowest diversity levels.

\section{Tree of Sequences: Maximum Parsimony}

A maximum parsimony tree was built in order to observe the phylogenetic structure in the sampled sequences. A mong all the possible maximum parsimonious trees, we represent in Figure 2 one which has a maximum number of sequences stemming from the most frequent substitutions ( 16126 and 16311). ${ }^{31} \mathrm{D}$ ark squares represent the intermediate steps not found in the present sample. In some cases more than one most parsimonious path leading to a sequence is shown. In this case some of the groups of sequences described by $\mathrm{R}$ ichards et $\mathrm{al}^{4}$ can be easily recognised. Nevertheless, we do not find strong support for any of the possible paths that may have generated these specific sequences.

M ost of the sequences in the tree stem directly from the reference sequence, with a few further mutations leading to other lineages. This high frequency of the reference sequence and the low number of substitutions that link it to many of the other lineages in $\mathrm{G}$ alicia is consistent with the clinal variation observed in E urope with higher values in Western E urope. ${ }^{31}$

Despite the simplicity of the tree and the lack of a robust structure, some clusters should be mentioned:

(a) the $C$ in position 16126, which defines a small cluster of sequences in the tree, has been found to be polymorphic in European and West A sian populations and its frequency is clinal along E urope: from $50 \%$ in the M iddle E ast to $7.5 \%$ in B asques. In the $\mathrm{G}$ alician population this polymorphism is present in $12 \%$ of the individuals sampled. This cluster of sequences corresponds to group 2 according to $\mathrm{R}$ ichards et $\mathrm{al}_{,}{ }^{4}$

(b) The $C$ at position 16311 has a worldwide distribution with a high frequency in A frican populations. Its frequency in European populations is estimated to be around $20 \%{ }^{31}$ and its frequency in Galicia is $10.9 \%$. No clear geographic patterns 
Table 2 Sequence divergence. Population sources: Galician (present study), Basque,18, 19 Welsh,4 Portuguese,19 Cornish, B avarian, ${ }^{4}$ N orthern German, 4 B ritish, 20 Spanish,19, 21 Tuscan,22 Turk, 4, 23, 24 M iddle Easters. ${ }^{25}$ A II values in all populations art based on the analysis of a fragment of 360 nucleotides, from 16024 to $16383^{12}$

\begin{tabular}{lrlllllll}
\hline & $\mathrm{N}$ & $\mathrm{K}$ & $\mathrm{A}$ & $\mathrm{B}$ & $\mathrm{C}$ & $\pi$ & $\mathrm{J}$ & $\mathrm{H}^{\prime}$ \\
\hline Galician & 92 & 53 & 56 & 3.13 & 0.869 & 0.0087 & 0.9295 & 0.865 \\
B asque & 106 & 52 & 52 & 2.95 & 0.819 & 0.0081 & 0.9362 & 0.863 \\
Welsh & 92 & 48 & 51 & 3.39 & 0.942 & 0.0094 & 0.9307 & 0.862 \\
Portuguese & 54 & 38 & 46 & 3.60 & 1.000 & 0.0100 & 0.9343 & 0.887 \\
Cornish & 69 & 45 & 52 & 3.89 & 1.080 & 0.0108 & 0.9650 & 0.925 \\
B avarian & 49 & 37 & 37 & 3.94 & 1.094 & 0.0109 & 0.9838 & 0.967 \\
N orthern G erman & 108 & 70 & 61 & 3.92 & 1.089 & 0.0109 & 0.9733 & 0.917 \\
B ritish & 100 & 71 & 67 & 4.45 & 1.236 & 0.0123 & 0.9760 & 0.930 \\
Spanish & 89 & 70 & 69 & 5.02 & 1.394 & 0.0139 & 0.9834 & 0.952 \\
Tuscan & 49 & 40 & 55 & 5.03 & 1.397 & 0.0140 & 0.9685 & 0.938 \\
Turk & 96 & 79 & 82 & 5.45 & 1.514 & 0.0151 & 0.9879 & 0.961 \\
M iddle E ast & 42 & 38 & 59 & 7.08 & 1.966 & 0.0197 & 0.9954 & 0.991 \\
\hline
\end{tabular}

$\mathrm{N}$ : sample size. $\mathrm{K}$ : number of different sequences found. $\mathrm{A}$ : number of variable nucleotides positions. $\mathrm{B}$ : mean nucleotide pairwis differences. $\mathrm{C}$ : percentage average pairwise difference per nucleotide. $\pi$ : nucleotide diversity. J : sequence diversity. $\mathrm{H}$ ': ratio of $\mathrm{H}$ (Shannon's index) to $\mathrm{H}_{\max }$ (maximum value of $\mathrm{H}$ for a given sample size).

have been observed. It is not clear that it is a robust cluster and sequences with this substitution may have arisen through alternative ways.
Most of the 53 different sequences present a single change compared to the reference sequence, whereas only four differ in six positions (Figure 3). If we

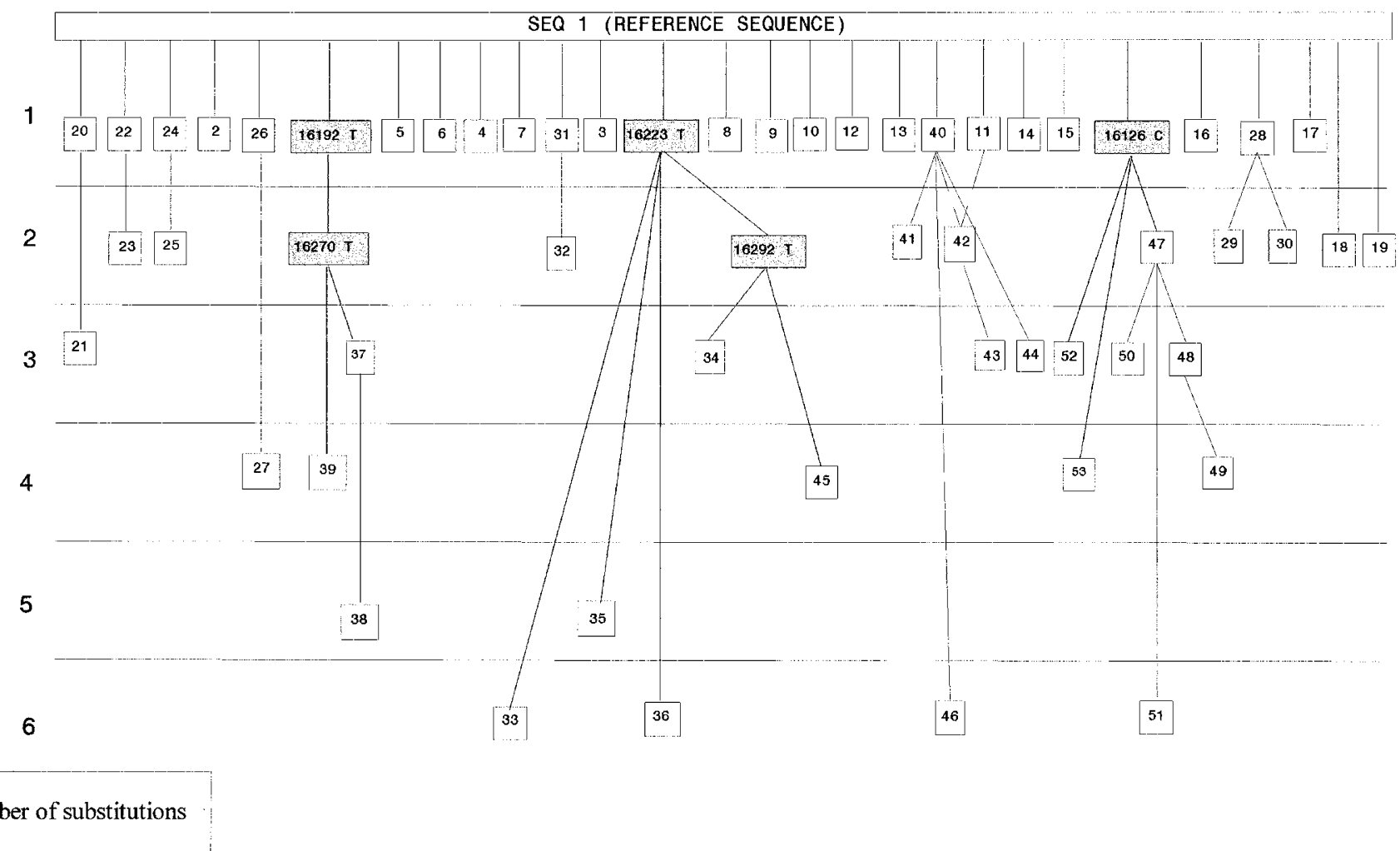

Figure 2 Maximum-parsimony tree of the sequences, where the reference sequence represents the ancestral sequence. The rest of sequences could have evolved from this one. Numbers at the left indicate differences to the reference sequence 
consider the possibility that the reference sequence is the ancestor of all the sequences, and assume that mutations accumulate in a Poisson process, ${ }^{32}$ the number of mutations relative to the reference would follow a Poisson distribution. From the sequences stemming from the reference by a single mutation, sequences have accumulated a further mean $\lambda=1.33$ mutations. A s shown in Figure 3, G alician sequences do not fit a Poisson distribution with such a high $\lambda$ value $\left(\chi^{2}=17.83\right.$, d.f. $\left.=5, P=0.003\right)$, having a clear overrepresentation of sequences with several substitutions. This could easily be understood if some variation had already existed in the founders of the $G$ alician population. This fact is also supported by the sharing of Galician sequences (SE Q 22, SE Q 28, SE Q 31, SE Q 40, SE Q 42, SE Q 43 and SE Q 47) by other European populations used for comparison. Nevertheless, the high frequency of the reference sequence in the present population is probably due to its high frequency in the founding population.

This lack of a branched structure and the star-like phylogeny found are compatible with a recent expansion of the $\mathrm{G}$ alician population ${ }^{33}$ and therefore, except for the deeper clusters found, most of the new haplotypes should have been produced in situ in recent times.

\section{Pairwise Differences}

The mean pairwise difference in Galicians is 3.13, a value slightly higher than the value found in $B$ asques and lower than the rest of E uropean and West A sian populations (Table 2). This value is merely the result of the low diversity of the $\mathrm{G}$ alician population, its lack of a complex tree structure and the phylogenetic proximity of its sequences. As shown in Table 2, a clinal

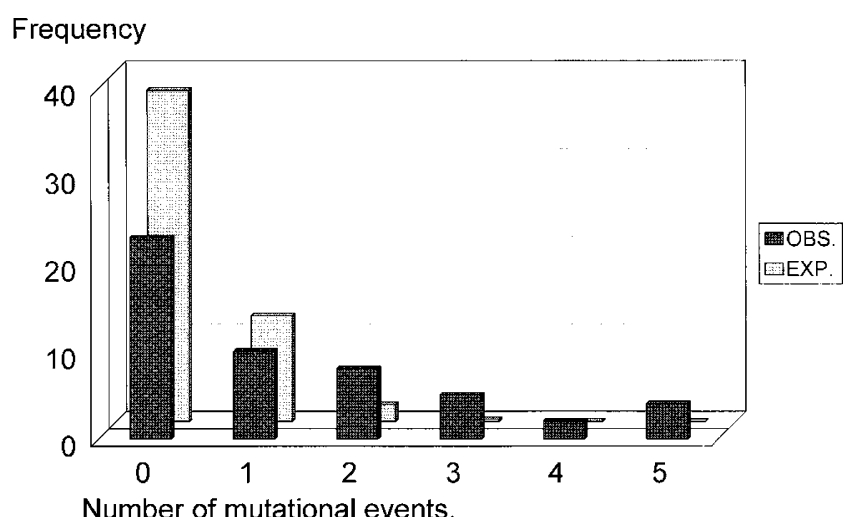

Figure 3 Expected and observed distributions of the number of mutational events occurred from the reference sequence in the $\mathrm{G}$ alician population decrease of this value is patent from the M iddle $E$ ast to the Basques and Galicians. This decrease towards Western E urope is compatible with an ancient expansion from the Middle East to the A tlantic coast, reaching $\mathrm{G}$ alicia, one of the last edges of the E uropean continent, in the last steps of the putative expansion. $O$ ther populations in the E uropean far west, such as the Welsh, also fit in this pattern.

The Galician pairwise difference distribution, Figure $4(\mathrm{~A})$, is clearly bell-shaped as expected in populations which have experienced a sudden expansion ${ }^{27}$ with a peak at only two differences. This empirical distribution is very robust, as shown by the small errors of the different values estimated by 1000 bootstrap

Frequency

(A)

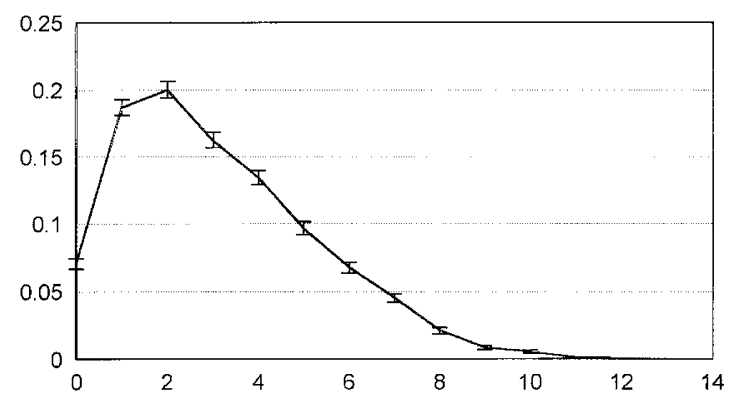

Number of differences

Frequency

(B)

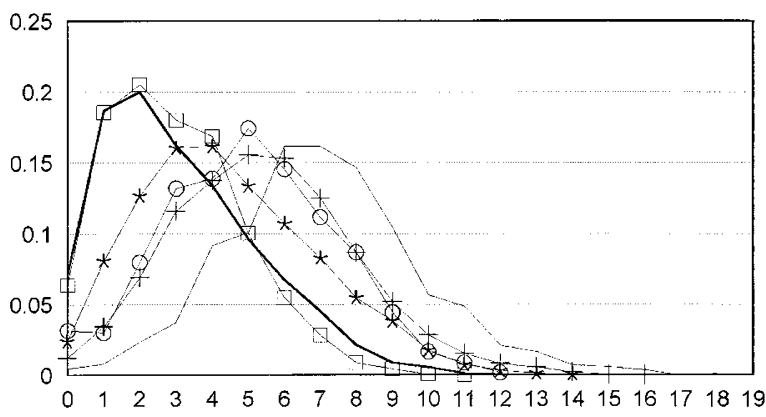

Number of differences

$$
\begin{array}{ll}
\text { - GALICIAN OTUSCAN } \forall \text { BASQUE } \\
+ \text { TURK } & * \text { BRITISH }- \text { MIDDLE-EAST }
\end{array}
$$

Figure 4 (A) Nucleotide pairwise difference distribution in $\mathrm{G}$ alician population. E rror bars were computed through 1000 bootstrap iterations. (B) Nucleotide pairwise differences distributions of some E uropean and West A sian populations used for comparison 
iterations. From the observed distribution, the $\tau$ parameter, related to time since the putative expansion, can be estimated from the theoretical model proposed by $\mathrm{H}$ arpending et al. ${ }^{17} \mathrm{In}$ the present population this $\tau$ value is estimated to be $1.913 \pm 0.045$ (standard error computed from 1000 bootstrap iterations), the lowest value found in the European and West A sian populations (Table 3). As the theoretical model proposes, $\tau$ would increase with time after the expansion of the populations. In Figure 4(B), several E uropean and West A sian pairwise difference distributions are shown. It can be seen that the peaks of the Western European populations remain at the left-hand side of the graph, whereas the West A sian populations tend to the right. The order of the peaks in the figure from left to right is Galician and Basque (with a very similar distribution), B ritish, Tuscan, Turk and M iddle E astern. This pattern is highly correlated with the geographical position of the populations analysed. A gain, the extreme position of Galicia within the European framework is shown.

\section{Population Tree}

Genetic distances between European and West A sian populations were calculated and a neighbour-joining tree was constructed. I ts robustness was assessed by 1000 bootstrap iterations (Figure 5). The tree displays West A sian populations ( $M$ iddle $E$ ast and Turks) at one edge, Galician-B asques-Welsh at the opposite end, and the rest of the populations in between. The robustness of the tree is especially strong at these two edges where over $64 \%$ of the bootstrapped trees are found: $M$ iddle E ast and Turks have a bootstrap support of $64.3 \%$, G alician and B asque, $66.8 \%$, and $\mathrm{G}$ alician, $\mathrm{B}$ asque and Welsh, $68.9 \%$. A s seen before, in the present tree a geographic gradient from the Middle E ast to the West A tlantic populations is also shown. H owever, it is worth stressing the position of the Spanish population, closer to Central European groups than to the other two

Table 3 Population expansion times and $\tau$ parameter from $\mathrm{R}$ ogers and $\mathrm{H}$ arpending 27 model for several populations (Central E urope included German, Bavarian and Tuscan). Two different mutation rates were used to estimate expansion time dates: $4.14 \times 10^{-6,10}$ and $2.06 \times 10^{-6}, 38$ The mean generation time was set to 20 years

\begin{tabular}{llll}
\hline & $\tau$ & $\mu=4.14 \times 10^{-6}$ & $\mu=2.06 \times 10^{-6}$ \\
\hline G alician & 1.913 & 12.835 & 25.796 \\
B asque & 2.258 & 15.150 & 30.448 \\
Central E urope & 3.495 & 23.450 & 47.128 \\
Turk & 4.502 & 30.206 & 60.707 \\
M iddle E ast & 7.019 & 47.101 & 94.647 \\
\hline
\end{tabular}

north Iberian groups. This fact might be due to an important bias as a result of grouping five different small samples from Spain in a single group of 89 individuals: 30 from northern Spain, 15 from Catalonia, 15 from A ndalusia, 11 scattered throughout Spain, ${ }^{19}$ and 18 Spanish mainlanders from different regions. ${ }^{21}$ When a neighbour-joining tree is built with these groups considered separately (data not shown), only one of the sub-samples (15 A ndalusians) is close to the West A sian groups. This fact produces the displacement of the total Spanish group to the central part of the tree. It will be interesting to clarify this point in the future.

\section{Site 73 in Hypervariable Region II}

It has been suggested ${ }^{34}$ that the nucleotide at position 73 of the hypervariable region $I I$ is a keystone in interpreting the E uropean variation, as lineages carrying an $\mathrm{A}$ at this position would be strongly related to a cluster stemming from the reference sequence (called group $1^{4}$ and group $H,{ }^{35}$ ) whereas the rest of the lineages would carry $a G$ at this site with few exceptions. ${ }^{35}$ The present results (see right-hand columns of Table 1) do not show the clear split of sequence clusters defined by position 73 . Of the 16 individuals with the reference sequence, thus supposed to belong to group $1^{4}$ or group $\mathrm{H}^{35}$ three (19\%) present a $\mathrm{G}$ at position 73. Furthermore, of the 19 individuals typed for position 73 supposed to belong to the rest of the groups, ${ }^{34,35}$ four $(21 \%)$ presented an A. Therefore, it seems reasonable not to rely completely on the

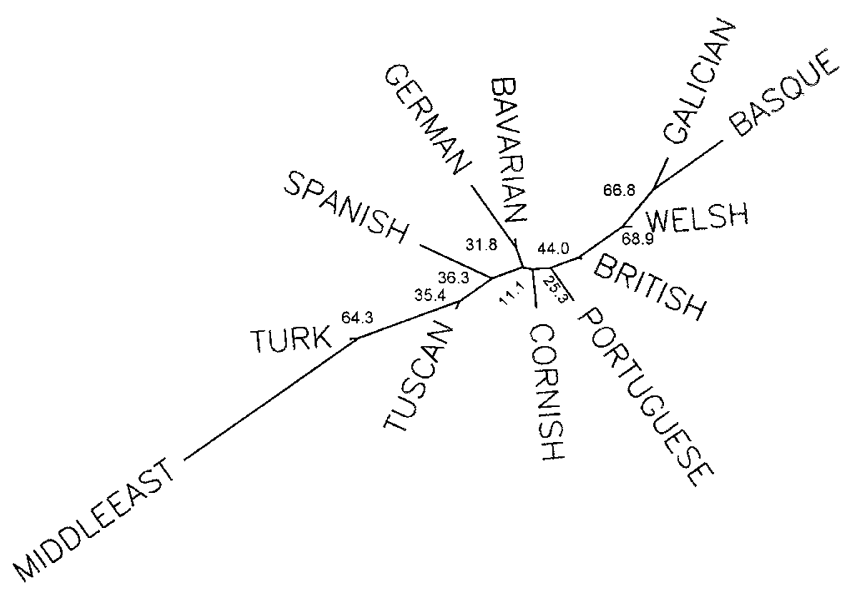

Figure 5 Neighbour-joining tree built from mismatch-intermatch distances. Numbers at the nodes indicate bootstrap supports after 1000 iterations 
significance of the specific nucleotide present at this single site.

\section{Discussion}

The present results are fully compatible with an expansion population model in Europe during the U pper Paleolithic ${ }^{5}$ which probably implies the replacement of the $\mathrm{Neanderthals} \mathrm{by} \mathrm{anatomically} \mathrm{modern}$ humans. They show the extreme similarity between the two populations situated at the edges of the Cantabrian region ( $G$ alicians and $B$ asques), which has been repeatedly shown by archaeologists to be a very homogenous area in prehistoric and mainly Paleolithic times. ${ }^{36} \mathrm{~A}$ llele frequency data, nonetheless, tended to show important differences between these two populations.

The present results show that $G$ alicians present a very low genetic diversity compared with the rest of the European populations. This is shown by the low nucleotide diversity, low sequence diversity and low Shannon index value. Moreover, the mean of the pairwise difference distribution is one of the lowest in Europe, and the frequency of the reference sequence reaches its maximum value in the present population.

The low genetic diversity indexes, the low mean pairwise differences, the simple maximum parsimony tree, the distance matrix between populations and the neighbour-joining tree of populations are compatible with an expansion into E urope from the Middle East, with $\mathrm{G}$ alicia at the edge of it. Figure $4 \mathrm{~B}$ shows that the pairwise difference distributions in Europe and West A sia are compatible with a relatively recent population expansion.

A II results are in accordance, as postulated by Comas et $\mathrm{al}^{5}{ }^{5}$ with an expansion wave from the Eastern European populations to the West. The $\tau$ values obtained from the $\mathrm{H}$ arpending model ${ }^{17}$ allows us to estimate this expansion for the $\mathrm{G}$ alician region between 13000 and 26000 years ago, depending on the mutation rates used. There is some debate on the mutation rate values for the control region of the mtDNA, ${ }^{37}$ with recent family data giving higher values than those obtained phylogenetically. ${ }^{10,38}$

A rchaeological data shows that the expansion of the A urignacian culture from Central Europe to the Cantabrian area was very fast ${ }^{39,40}$ and therefore it is unlikely that the cultural expansion would have been related to a demographic expansion and substitution. The demographic replacement of the area should have been posterior to the cultural replacement of the initial U pper Paleolithic, and it was homogenous in all of the Cantabrian coast. This replacement might be dated around the Last Glacial Maximum (LGM) - the Solutrean period 18000 years ago ${ }^{41}$ - when environmental conditions contributed to the isolation of groups. This isolation was postulated to have been particularly strong amongst the $B$ asque population but now it also appears clearly in all the narrow $C$ antabrian littoral. The availability of marine resources in the Cantabrian coast and the relatively hospitable physical environment during the LGM allowed a relatively high population density in the area. ${ }^{42}$

The striking genetic similarity between $\mathrm{G}$ alicians and Basques at the mtDNA level may seem difficult to match with the great differences found in allele frequency studies with classic genetic markers. ${ }^{6,43}$ Nonetheless, different sources of genetic data may explain different population events, and be compatible beyond apparent discrepancies. A llele frequencies are deeply affected by drift when population size is small and the stochastic nature of drift is likely to accumulate differences through time. Sequence composition, on the other hand, is much less prone to be influenced by population size and thus both populations could have had a similar origin in the late U pper Paleolithic. The passage of time until the late $\mathrm{N}$ eolithic growth would have allowed the two populations to diverge in allele frequency terms, preserving nonetheless the same basic mtDNA composition which does not seem to have much altered later in time.

In the specific case of Galicia, some archaeological events may be worth considering, keeping in mind that the whole Cantabrian area seems to have had a common heritage in prehistory. The effect of the Neolithic may now be envisaged as having had a poor population substitution in A tlantic E urope according to the availability model, ${ }^{44}$ especially in the Cantabrian region. ${ }^{45} \mathrm{~A}$ nother important archaelogical event, often referred to as 'C eltic influences' in G alicia coming from the North A tlantic coast during the first millenium BC seems to have been produced by an elite contact with a small demographic effect. ${ }^{7,46}$ Nonetheless, only if the migration had been quantitatively important could it have been detected by the present analysis due to the high homology of the mID NA in the A tlantic E uropean populations as a result of the Paleolithic expansion from the M iddle East.

The genetic analysis of single populations may help not only to reconstruct the patterns of human history 
but also, as in the present case, to understand discrepancies between different genetic analyses.

\section{Acknowledgements}

This work was supported in part by grants from the $D$ irección G eneral de Investigación Científico Técnica (PB 95-0267-C 0201 ) and from the Direcció G eneral de R ecerca, Generalitat de Catalunya (1996SGR 00041) awarded to JB and DC and the grant from the $X$ unta de Galicia ( $X \cup G A$ 20801B 95), given to $M V L, A S$, and $A C$. The help of $F$ Calafell and $R$ Ward is also acknowledged with appreciation. $\mathrm{H}$ ans $\mathrm{B}$ andelt made an invaluable revision of the manuscript.

\section{References}

1 Cavalli-Sforza LL, M enozzi P, Piazza A : H istory and $\mathrm{G}$ eography of $\mathrm{H}$ uman $\mathrm{G}$ enes. Princeton U niversity Press, Princeton, 1994.

$2 \mathrm{H}$ arding RM, Fullerton SM, Griffiths R C et al: A rchaic $A$ frican and $A$ sian lineages in the genetic ancestry of modern humans. A m J H um G enet 1997; 60: 772-789.

3 Sajantila A, Lahermo P, A nttinen T et al: Genes and languages in Europe: an analysis of mitochondrial lineages. G enome Res 1995; 5: 42-52.

4 R ichards M, Côrte R eal H, Forster P et al: Paleolithic and Neolithic lineages in the European mitochondrial gene pool. A m J H um G enet 1996; 59: 185-203.

5 Comas D, Calafell F, M ateu E, Pérez-L ezaun A, B osch E, Bertranpetit J: Mitochondrial DNA variation and the origin of the E uropeans. Hum G enet 1997; 99: 443-449.

6 Calafell F, B ertranpetit J : Principal component analysis of gene frequencies and the origin of Basques. Am J Phys Antrop 1994; 93: 201-215.

7 Ruiz-Gálvez M: Canciones del muchacho viajero. Veleia 1990 7: 79-103.

8 Sherratt A: Plough and pastoralism: aspects of the secondary products revolution. In: Hodder I, Isaac G, $\mathrm{H}$ ammond $\mathrm{N}$ (eds): Patterns of the Past. Cambridge U niversity Press, C ambridge, 1981.

9 Valverde E, Cabrero C, Cao R et al: Population genetics of three VNTR polymorphisms in two different Spanish populations. Int J Legal Med 1993; 151: 251-256.

10 Ward RH, Frazier BL, D ew-Jager K, Pääbo S: Extensive mitochondrial diversity within a single A merindian tribe. Proc Natl A cad Sci USA 1991; 88: 8720-8724.

11 Vigilant $L$, Pennington $R, H$ arpending $H$, Kocher TD: $M$ itochondrial DNA sequences in single hairs from a southern A frican population. Proc Natl Acad Sci USA 1989; 86: 9350-9354.

12 A nderson S, Bankier A T, B arrell BG et al: Sequence and organisation of the human mitochondrial genome. Nature 1981; 290: 457-465.

13 Thompson JD, Higgins DG, Gibson TJ: Clustal W: Improving the sensitivity of progressive multiple sequence alignment through sequence weighting, position-specific gap penalties and weight matrix choice. Nud Acid Res 1994; 22: 4673-4680.

14 Felsenstein J: PHY LIP - Phylogeny Inference Package (Version 3.2). Cladistics 1989; 5: 164- 166.
$15 \mathrm{Nei} \mathrm{M}$, Tajima F: DNA polymorphism detectable by restriction endonucleases. G enetics 1981; 97: 145-163.

16 Magurran AE: Ecological Diversity and its Measure. Princeton U niversity Press, Princeton, 1988.

$17 \mathrm{H}$ arpending $\mathrm{HC}$, Sheny ST, R ogers A R, Stoneking M : The genetic structure of ancient human populations. Curr A nthrop 1993; 34: 483-496.

18 Bertranpetit J, Sala I, Calafell F, U nderhill P, M oral P, Comas D: H uman mitochondrial DNA variation and the origin of the Basques. A nn H um G enet 1995; 59: 63-81.

19 Côrte-Real HBSM, Macaulay VA, Ricards MB et al: Genetic diversity in the Iberian Peninsula determined from mitochondrial sequence analysis. Ann Hum Genet 1996; 60: 31-350.

20 Piercy R, Sullivan KM, Benson N, and Gill P: The application of mitochondrial DNA typing to the study of white Caucasian genetic identification. Int J Leg Med 1996; 106: 85-90.

21 Pinto F, G onzález A M , H ernánez M , L arruga J M , C abrera VM: $G$ enetic relationship between the $C$ anary Islanders and their A frican and Spanish ancestors inferred from mitochondrial D NA sequences. A nn H um G enet 1996; 60: 321-330.

22 Francalacci P, Bertranpetit J, Calafell F, U nderhill PA: Sequence diversity of the control region of mitochondrial DNA in Tuscany and its implications for the peopling of E urope. A m J Phys A nthrop 1996; 100: 443-460.

23 Calafell F, U nderhill P, Tolun A, A ngelicheva D, Kalaydjieva L: From A sia to Europe: mitochondrial DNA sequence variability in Bulgarians and Turks. Ann Hum Genet 1996; 60: 35-49.

24 Comas D, Calafell F, M ateu E, Pérez-L ezaun, B ertranpetit $\mathrm{J}$ : Geographic variation in human mitochondrial DNA control region sequence: the population history of Turkey and its relationship to the E uropean population. M ol Biol Evol 1996; 13: 1067-1077.

25 Di Rienzo A, Wilson AC: Branching pattern in the evolutionary tree for human mitochondrial DNA. Proc Natl A cad Sci USA 1991; 88: 1597-1601.

26 R ao CR : D iversity and dissimilarity coefficients: a unified approach. Theor Popul Bio 1982; 21: 24-43.

27 Rogers A R, Harpending $H$ : Population growth makes waves in the distribution of pairwise genetic differences. Mol Biol Evol 1992; 9: 552-569.

28 Efron B: The Jackknife, the Bootstrap and other Resampling Plans. Society for Industrial and A pplied Mathematics, Philadelphia, 1982.

29 Felsenstein J: Confidence limits on phylogenies: an approach using the bootstrap. Evolution 1985; 39: 785-791.

30 Wakeley J: Substitution rate variation among sites in hypervariable region 1 of human mitochondrial DNA.J Mol Evol 1993; 37: 613-623.

31 Bertranpetit J, Calafell $F$, Comas D, Pérez-L ezaun A, $M$ ateu $E$ : $M$ itochondrial DNA sequences in Europe: an insight into population history. In: AJ Boyce and CGN Mascie-Taylor (eds): Molecular Biology and Human Diversity. Cambridge U niversity Press, Cambridge, 1996, pp112-129.

32 Hudson R R: G ene genealogies and the coalescent process. Oxford Surveys in evolutionary biology 1990; 7: $1-44$. 
33 Slatkin M, H udson R: Pairwise comparisons of mitochondrial DNA sequences in stable and exponentially growing populations. G enetics 1991; 129: 555-562.

34 Wilkinson-H erbots H M, R ichards M B, Forster P, Sykes C: Site 73 in hypervariable region II of the human mitochondrial genome and the origin of $E$ uropean populations. A nn H um G enet 1996; 60: 499-508.

35 Torroni A, H uoponen K, Francalacci P et al: Classification of $E$ uropean $m t D N A$ s from an analysis of three $E$ uropean populations. G enetics 1996; 144: 1835-1850.

36 Straus LG: U pper Paleolithic origins and radiocarbon calibration: more new evidence from Spain. Evolutionary A nthropology 1994; 2: 195-198.

37 Parsons TJ, M uniec DS, Sullivan $K$ et al: $A$ high observed substitution rate in the human mitochondrial DNA control region. N at G enet 1997; 15: 363-368.

$38 \mathrm{H}$ orai S, Hayasaka K, Kondo R, Tsugane K, Takahata N: $R$ ecent $A$ frican origin of modern humans revealed by complete sequences of hominoid mitochondrial DNAS. Proc Natl A cad Sci USA 1995; 92: 532-536.

39 Cabrera V, Bischoff J: A ccelerator ${ }^{14} \mathrm{C}$ ages for basal A urignacian at EI Castillo, Spain. J A rchaeol Sci 1989; 16: $577-584$
40 Straus L G : A ge of modern E uropeans. N ature 1989; 342: 476-477.

41 Soffer O, Gamble C (eds): The World at 18000 BP. U nwin $\mathrm{H}$ yman, L ondon, 1990.

42 Straus LG: Southwestern Europe at the Last G lacial M aximum. Current A nthropology 1991; 32: 189-199.

43 Bertranpetit J, Cavalli-Sforza LL: A genetic reconstruction of the history of the population of the Iberian Peninsula. A nn H um G enet 1991; 55: 51-67.

44 Zvelebil M, Rowley-Conwy PR : Foragers and farmers in A tlantic E urope. In: M Z velebil (ed). H unters in Transition. Cambridge U niversity Press, Cambridge, 1986, pp67-93.

45 A rias P: De cazadores a campesinos. $L$ a Transición al Neolítico en la región Cantábrica. U niversidad de Cantabria, Santander, 1991.

46 Sherratt $A$ : The emegence of élites: earlier Bronze $A$ ge Europe, 2500-1300 BC. In: Cunliffe B (ed): The Oxford Illustrated Prehistory of E urope. Oxford U niversity Press, Oxford, 1994, pp244-276. 